\title{
Characterization of Hepatocellular Carcinoma Patients with FGF19 Amplification Assessed by Fluorescence in situ Hybridization: A Large Cohort Study
}

\author{
Hyo Jeong Kang ${ }^{a}$ Farhan Haq $^{b}$ Chang Ohk Sung ${ }^{a}$ Jene Choi ${ }^{a}$ \\ Seung-Mo Hong ${ }^{a}$ Soo-Heang Eo ${ }^{c}$ Hui Jeong Jeong ${ }^{a}$ Jinho Shin $^{a}$ \\ Ju Hyun Shim ${ }^{d}$ Han Chu Leed Jihyun An ${ }^{d}$ Mi-Ju Kim ${ }^{e}$ Kyu-pyo Kim ${ }^{f}$ \\ Sung-Min Ahng Eunsil Yu ${ }^{a}$ \\ a Department of Pathology, Asan Medical Center, University of Ulsan College of Medicine, \\ Seoul, Republic of Korea; ${ }^{b}$ Department of Biosciences, COMSATS Institute of Information \\ and Technology, Islamabad, Pakistan; ' Department of Statistics, Korea University, Seoul, \\ Republic of Korea; ${ }^{d}$ Department of Gastroenterology, Asan Liver Center, Asan Medical \\ Center, University of Ulsan College of Medicine, Seoul, Republic of Korea; ${ }^{\mathrm{e}}$ Asan Institute for \\ Life Sciences, Asan Medical Center, University of Ulsan College of Medicine, Seoul, Republic \\ of Korea; ${ }^{f}$ Department of Oncology, Asan Medical Center, University of Ulsan College \\ of Medicine, Seoul, Republic of Korea; ${ }^{9}$ Department of Hematology-Oncology, Gachon \\ Institute of Genome Medicine and Science, Gachon University Gil Medical Center, Incheon, \\ Republic of Korea
}

\section{Keywords}

FGF19 · Fluorescence in situ hybridization · Hepatocellular carcinoma · High copy number amplification · Prognosis

\begin{abstract}
Background: FGF19 amplification is a relatively novel type of genetic aberration that has been proposed to be a driver of hepatocarcinogenesis. Selective inhibitors of FGFR4, a receptor of FGF19, have been developed as targeted therapies for hepatocellular carcinoma (HCC). Despite the role of FGF19 in mediating HCC progression, the clinicopathological characterization of patients exhibiting FGF19 amplification remains unclear. Immunohistochemical staining is the simplest and most widely used method of identifying aberrations in the FGF19 gene, although its specificity is very low. Methods: This study investigated the prognostic significance of FGF19 amplification in a large cohort of 989 HCC patients using fluorescence in situ hybridization (FISH), which has a high degree of specificity. In addition, FISH data from formalinfixed, paraffin-embedded sections were compared with copy number variation (CNV) data
\end{abstract}

Hyo Jeong Kang and Farhan Haq contributed equally to the work described in this paper.

Sung-Min Ahn, Department of Hematology-Oncology Gachon University Gil Medical Center

Namdong-daero, Namdong-gu

Incheon 21565 (Republic of Korea)

E-Mailsmahn@gachon.ac.kr
Eunsil Yu, Department of Pathology

Asan Medical Center, University of Ulsan College of Medicine 88 Olympic-ro 43 gil, Songpa-gu

Seoul 05505 (Republic of Korea)

E-Mail d890075@gmail.com 


\section{Liver Cancer}

Kang et al.: Characterization of HCC Patients with FGF19 Amplification

obtained from fresh frozen sections to validate the use of FISH as a diagnostic tool. Results: FGF19 amplifications were detected by FISH in 51 (5.15\%) of the 989 patients, and were independently associated with poor survival and a higher risk of tumor recurrence, as well as with poor prognostic factors such as a high $\alpha$-fetoprotein level, hepatitis B or C virus infection, a large tumor size, microvascular invasion, and necrosis. In addition, FGF19 amplification was associated with TP53 mutation, and was mutually exclusive with CTNNB1 mutation. The results of the FISH and CNV analyses exhibited a significant concordance rate of $96 \%$ ( $\mathrm{K}=0.618$, $p$ < 0.001). Conclusions: These data indicate that FGF19 amplification represents a unique molecular subtype associated with poor prognostic characteristics, which supports the hypothesis that the FGF19-FGFR4 signaling pathway plays an important role in hepatocarcinogenesis. We have also demonstrated that FISH is a viable alternative to CNV analysis, offering a number of advantages in the clinical setting.

(c) 2018 S. Karger AG, Basel

\section{Introduction}

Hepatocellular carcinoma (HCC) is the third most frequent cause of cancer-related mortality worldwide and its incidence is associated with hepatitis B and/or C infection, alcoholism, and metabolic syndrome [1]. Recent genomic studies have demonstrated that hepatocarcinogenesis involves genetic and epigenetic changes in multiple molecular pathways [2-6]. For example, somatic mutations in the TP53 and TERT promoter regions have been identified as major mechanisms by which HCC progression can be facilitated [7, 8]. Similarly, aberrant methylation of SEPT9 and/or EFNB2 has been reported to drive hepatocarcinogenesis at the epigenetic level [9], and copy number amplification (e.g., FGF19) and deletion (e.g., $R b$ deletion) of certain genes are also associated with hepatocarcinogenesis $[2,10,11]$.

FGF19 amplification was recently identified as a genetic aberration that may promote hepatocarcinogenesis $[12,13]$. Normally, FGF19 binds to FGFR4 on the surface of hepatocytes and regulates bile acid metabolism [14]; the activation of this pathway also leads to hepatocyte proliferation [15]. Accordingly, FGF19 amplification results in the abnormal proliferation of hepatocytes, thereby driving hepatocarcinogenesis and leading to the development of HCC [16, 17]. As a result, selective FGFR4 inhibitors have been investigated as potential targeted therapies for HCC associated with FGF19 amplification or overexpression $[3,18,19]$. However, studies that have demonstrated an association between FGF19 amplification and poor HCC prognosis have had notable limitations, such as small study populations or low sensitivity and specificity associated with the immunohistochemistry used to detect $F G F 19$ expression $[13,16,20]$.

In a previous study of 231 cases of HCC, we reported the potential clinical relevance of FGF19 amplification for patient stratification [10]. In our current study, we have examined the presence of FGF19 amplification further, using fluorescence in situ hybridization (FISH) analysis in a large cohort of 989 HCC patients. Our main goal was to investigate the prognostic significance of FGF19 amplification in HCC using FISH. In addition, FISH data obtained from formalin-fixed, paraffin-embedded sections were compared with copy number variation (CNV) data obtained from fresh frozen sections to validate the use of FISH as a diagnostic tool.

\section{Subjects and Methods}

Patients and Samples

This retrospective study included a large cohort of 989 patients diagnosed with HCC by surgical resection at the Asan Medical Center, Seoul, Republic of Korea, between 2005 and 2013. All clinical information was 


\section{Liver Cancer}
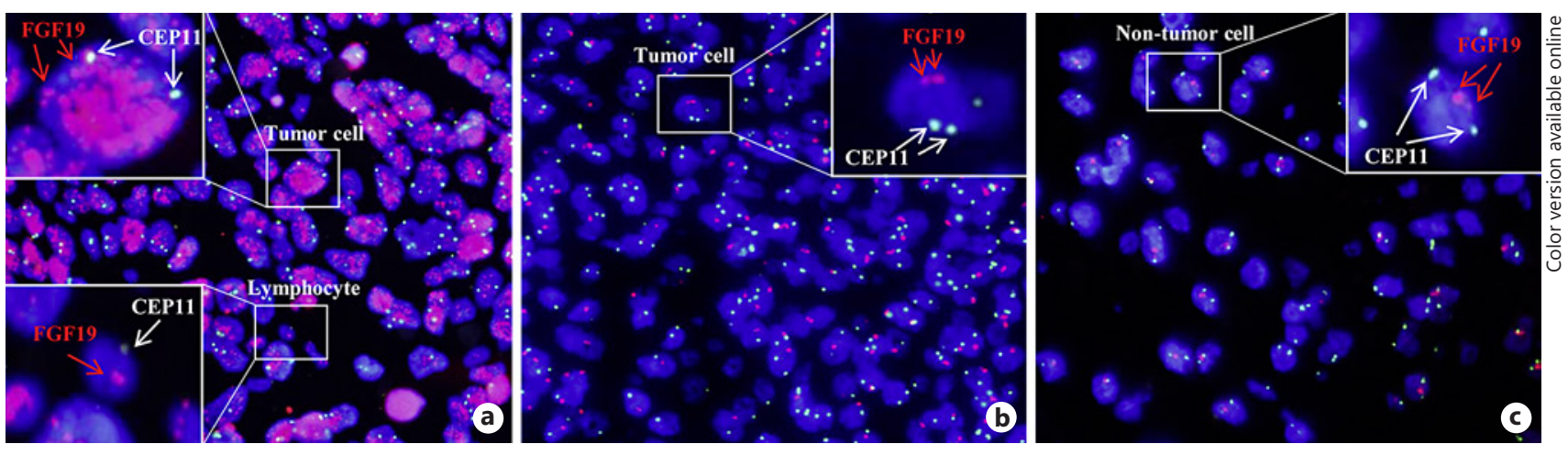

Fig. 1. Fluorescence in situ hybridization micrographs showing FGF19 (red signal) and CEP11 (green signal) fluorescence in tumor cells and non-tumor cells. a FGF19 positive in tumor cells: an increase in the number of red signals in tumor cells, indicating amplification of FGF19 (left upper inset). Normal FGF19 or CEP11 signals served as the internal positive control in lymphocytes (left lower inset). Magnification, $\times 1,000$. b, c FGF19 negative in tumor cells (b) and FGF19 negative in non-tumor cells (c): no increase in red signals in tumor and non-tumor cells, indicating no amplification of FGF19, respectively (insets). Magnification, $\times 1,000$.

collected from the database of the Asan Liver Center. The 989-patient cohort included 227 patients from our previous study, and the results of the FGF19 CNV analysis obtained from these patients were used in this study [10]. The median follow-up time was 56 months (range 0-148). The study was approved by the Institutional Review Board of the Asan Medical Center (IRB No. 2017-0875).

\section{Tissue Microarrays}

All slides and histological data were reviewed by two pathologists (E.Y. and H.J.K.). A total of 56 tissue microarrays were prepared from formalin-fixed, paraffin-embedded tissue samples. In brief, two cores from tumorous tissue and one core from nonneoplastic liver tissue (both with a diameter of $2.0 \mathrm{~mm}$ ) were sampled for each HCC case and placed into recipient blocks with holes made by an arraying machine (TMArrayer; Pathology Devices, Westminster, MD, USA).

\section{FGF19 Fluorescence in situ Hybridization}

Consecutive 5- $\mu \mathrm{m}$ sections were cut from the microarray blocks. FISH was performed with two probes targeting FGF19 and CEP11 (Abbott Molecular, Des Plaines, IL, USA) on tissue microarrays, according to the manufacturer's recommendations. The slides were examined with an Olympus BX51 fluorescence microscope (Olympus, Tokyo, Japan) using a 100x objective. Each image was obtained through fluorescence isothiocyanate and Texas Red band-pass filters on an Olympus DP70 camera and analyzed using DP Controller software (version 3.3.1.292).

\section{Scoring Criteria}

The two experienced pathologists (E.Y. and H.J.K.) independently interpreted all FISH slides. Discordant cases were resolved by reevaluation of the FGF19 FISH status on whole sections. Normal FGF19 or CEP11 signals served as the internal positive control in lymphocytes (Fig. 1a). The FISH signals were visualized as single copies, multiple copies, and clusters. A discrete dot was counted as a single copy of FGF19 or CEP11. The size of these single dots was used as a reference to determine the relative number of amplified copies in the cancer cell nuclei. In some nuclei, clusters of dots representing many copies of the FGF19 gene were apparent. In such cases, a small cluster of multiple signals was counted as 6 signals and a large cluster was counted as 12 signals. The results were determined according to the American Society of Clinical Oncology/ College of American Pathologists (ASCO/CAP) 2013 guidelines and interpreted as positive, equivocal, or negative [21].

FGF19 and CEP11 signals were enumerated in this manner in 50 cell nuclei within a given HCC area, and the FGF19/CEP11 ratio was calculated. All cases were visually assessed, and classified as FGF19 positive if they met the following criteria: (1) dual-probe FGF19/CEP11 ratio $\geq 2.0$ with an average FGF19 copy number 
Kang et al.: Characterization of HCC Patients with FGF19 Amplification

$\geq 4.0$ signals/cell; (2) dual-probe $F G F 19 / C E P 11$ ratio $\geq 2.0$ with an average $F G F 19$ copy number $<4.0$ signals/ cell; or (3) dual-probe FGF19/CEP11 ratio $<2.0$ with an average $F G F 19$ copy number $\geq 6.0$ signals/cell. They were interpreted as FGF19 negative if the dual-probe FGF19/CEP11 ratio was $<2.0$ with an average FGF19 copy number $<4.0$ signals/cell. Results such as a single-probe FISH average FGF19 copy number $\geq 4.0$ and $<$ 6.0 signals/cell or a dual-probe $F G F 19 / C E P 11$ ratio $<2.0$ with an average FISH FGF19 copy number $\geq 4.0$ and $<6.0$ signals/cell were interpreted as equivocal. For these results, an additional examination was performed in 50 nuclei at a different site from those initially observed. The FGF19/CEP11 ratio was then calculated in a total of 100 cell nuclei from the first and the second site.

\section{Somatic Mutation and CNV Analysis}

The results of the FGF19FISH were compared with the data on somatic mutations and CNV data obtained in our previous study [10]. The platform used in the previous study was the Affymetrix CytoScan HD Array. As previously noted, CNV analyses were performed using the Nexus Copy Number software (version 6.1; BioDiscovery, El Segundo, CA, USA) with default parameters. In addition, whole exome sequencing data from 28 significantly mutated genes (TP53, CTNNB1, HMCN1, PCLO, ADGRV1, LRP1B, APOB, RYR3, VCAN, SYNE1, DNAH6, RYR2, FBN2, XIRP2, PKHD1L1, C17ORF97, FLG, OBSCN, AXIN1, KIAA1109, AHNAK2, MGAM, CENPF, COL7A1, COL6A6, PXDN, KMT2D, and RB1), which had shown a frequency of more than $5 \%$ in our previous study, were included in this evaluation.

\section{Statistical Analysis}

Statistical analyses were performed using the SPSS statistical software program (version 18.0; SPSS Inc., Chicago, IL, USA). Concordance rates between the different methods were determined and $\kappa$ statistics were calculated using Cohen's kappa coefficient, according to which a $\kappa$ value of 1 denotes complete agreement, a value of 0.75 denotes excellent agreement, values between 0.4 and 0.75 denote fairly good agreement, and values $<0.4$ denote poor agreement. A $\chi^{2}$ test was performed to compare the frequencies of categorical variables between the groups.

The overall survival (OS) was designated to extend from the day of surgical tumor resection to the date of the patient's death from any cause. The follow-up period for the surviving patients was assessed from the last follow-up date. Disease-free survival (DFS) was assessed as the length of time from the day of surgical tumor resection to disease recurrence or the last follow-up date. Both the OS and DFS times were calculated by the Kaplan-Meier method, and their statistical significance was evaluated by the log-rank test and the Cox proportional-hazards regression model. All tests were two-sided, and $p$ values $<0.05$ were considered to indicate statistical significance.

\section{Results}

\section{Clinicopathological Characteristics}

Table 1 summarizes the patient characteristics and pathologic features of the evaluated tumors. The mean patient age at diagnosis was 56 years (range 25-83) and 790 patients (79.9\%) were male. Recurrence occurred in 529 patients $(53.5 \%)$ and early recurrence within 2 years in 464 (46.9\%). The estimated 5-year OS and DFS rates were 405 (40.9\%) and 317 (32.0\%), respectively.

\section{Correlation between FGF19 Amplification by FISH and Clinicopathological Variables}

The results of FGF19 FISH in tumor cells were positive in 51 cases (5.16\%; Fig. 1a) and negative in 938 cases (94.84\%; Fig. 1b). No cases showed FGF19 amplification in nontumorous cells (Fig. 1c). FGF19 amplification was significantly correlated with high serum $\alpha$-fetoprotein levels $(p=0.001)$, hepatitis B or C virus infection $(p=0.030)$, a tumor size $>5$ $\mathrm{cm}(p=0.003)$, microvascular invasion $(p=0.012)$, necrosis $(p=0.030)$, and early disease recurrence ( $p=0.010$; Table 2). In contrast with our previous observations, FGF19 amplification showed no association with cirrhosis $(p=0.386)$. An analysis comparing the FISH results with our previously published whole exome sequencing data revealed that FGF19 


\section{Liver \\ Cancer}

Table 1. Demographic summary of the study patients and characteristics of the hepatocellular carcinoma samples $(n=989)$

\begin{tabular}{l|l}
\hline Liver Cancer 2019;8:12-23 \\
\hline DOI: 10.1159/000488541 & $\begin{array}{l}\text { @ 2018 S. Karger AG, Basel } \\
\text { www.karger.com/lic }\end{array}$ \\
\hline
\end{tabular}

Kang et al.: Characterization of HCC Patients with FGF19 Amplification

\begin{tabular}{|c|c|}
\hline Age, years & $56(25-83)$ \\
\hline$\leq 50$ years & $292(29.5)$ \\
\hline$>50$ years & $697(70.5)$ \\
\hline \multicolumn{2}{|l|}{ Sex } \\
\hline Male & 790 (79.9) \\
\hline Female & $199(20.1)$ \\
\hline Serum AFP, ng/mL & $12,970.81(0.41-1,284,740.0)$ \\
\hline$\leq 100 \mathrm{ng} / \mathrm{mL}$ & $590(59.7)$ \\
\hline$>100 \mathrm{ng} / \mathrm{mL}$ & $399(40.3)$ \\
\hline \multicolumn{2}{|l|}{ Hepatitis virus } \\
\hline Hepatitis B & $824(83.3)$ \\
\hline Hepatitis C & $54(5.5)$ \\
\hline NBNC & $111(11.2)$ \\
\hline \multicolumn{2}{|l|}{ Liver cirrhosis } \\
\hline Absent & $433(43.8)$ \\
\hline Present & $556(56.3)$ \\
\hline Tumor diameter, $\mathrm{cm}$ & $5.33(0.7-22.0)$ \\
\hline$\leq 5 \mathrm{~cm}$ & $625(63.2)$ \\
\hline$>5 \mathrm{~cm}$ & $364(36.8)$ \\
\hline \multicolumn{2}{|l|}{ Multiplicity } \\
\hline Solitary tumor & 863 (87.3) \\
\hline Multiple tumors & $126(12.7)$ \\
\hline \multicolumn{2}{|c|}{ Edmondson-Steiner grade (worst) } \\
\hline I or II & $261(26.4)$ \\
\hline III or IV & $728(73.6)$ \\
\hline \multicolumn{2}{|l|}{ Microvascular invasion } \\
\hline Absent & $613(62.0)$ \\
\hline Present & $376(38.0)$ \\
\hline \multicolumn{2}{|c|}{ Glisson capsule invasion } \\
\hline Absent & $842(85.1)$ \\
\hline Present & $147(14.9)$ \\
\hline \multicolumn{2}{|l|}{ Necrosis } \\
\hline Absent & $523(52.9)$ \\
\hline Present & $466(47.1)$ \\
\hline \multicolumn{2}{|l|}{ Child-Pugh class } \\
\hline $\mathrm{A}$ & $935(94.5)$ \\
\hline B & $46(4.7)$ \\
\hline $\mathrm{C}$ & $8(0.8)$ \\
\hline \multicolumn{2}{|l|}{ BCLC stage } \\
\hline 0 & $49(5.0)$ \\
\hline A & $692(70.0)$ \\
\hline B & $103(10.4)$ \\
\hline $\mathrm{C}$ & 137 (13.9) \\
\hline D & $8(0.8)$ \\
\hline
\end{tabular}

Values are presented as $n(\%)$ or mean (range). AFP, $\alpha$-fetoprotein; NBNC, neither hepatitis B virus nor hepatitis $C$ virus.

amplification was significantly associated with TP53 mutations $(p=0.040)$ and mutually exclusive with CTNNB1 mutations ( $p<0.001$; Fig. 2).

\section{Prognostic Significance of FGF19 Amplification}

FGF19 amplification was significantly associated with lower 5-year OS (43.70\% in FGF19positive vs. $71.01 \%$ in FGF19-negative patients, $p<0.001$; Fig. 3a) and lower 5-year DFS (26.26\% in FGF19-positive vs. 44.97\% in FGF19-negative patients, $p<0.001$; Fig. 3b). Univariate analysis showed that FGF19 amplification was inversely associated with OS 


\section{Liver \\ Cancer}

Table 2. Correlation between FGF19 amplification and clinicopathological characteristics

\begin{tabular}{|c|c|}
\hline \multicolumn{2}{|l|}{ Liver Cancer 2019;8:12-23 } \\
\hline DOI: $10.1159 / 000488541$ & $\begin{array}{l}\text { (c) } 2018 \text { S. Karger AG, Basel } \\
\text { www.karger.com/lic }\end{array}$ \\
\hline
\end{tabular}

Kang et al.: Characterization of HCC Patients with FGF19 Amplification

\begin{tabular}{|c|c|c|c|}
\hline & $\begin{array}{l}F G F 19 \\
\text { negative } \\
(n=938)\end{array}$ & $\begin{array}{l}F G F 19 \\
\text { positive } \\
(n=51)\end{array}$ & $p$ \\
\hline Age & & & 0.082 \\
\hline$\leq 50$ years old & $271(28.9)$ & $21(41.2)$ & \\
\hline$>50$ years old & 667 (71.1) & $30(58.8)$ & \\
\hline Sex & & & 0.857 \\
\hline Male & $750(80.0)$ & $40(78.4)$ & \\
\hline Female & $188(20.0)$ & $11(21.6)$ & \\
\hline Serum AFP & & & $0.001^{*}$ \\
\hline$\leq 100 \mathrm{ng} / \mathrm{mL}$ & $571(60.9)$ & $19(37.3)$ & \\
\hline$>100 \mathrm{ng} / \mathrm{mL}$ & $367(39.1)$ & $32(62.7)$ & \\
\hline Hepatitis virus & & & $0.030^{*}$ \\
\hline Hepatitis B virus & $777(82.8)$ & 47 (92.2) & \\
\hline Hepatitis $\mathrm{C}$ virus & $50(5.3)$ & $4(7.8)$ & \\
\hline NBNC & $111(11.8)$ & $0(0.0)$ & \\
\hline Liver cirrhosis & & & 0.386 \\
\hline Absent & $414(44.1)$ & $19(37.3)$ & \\
\hline Present & $524(55.9)$ & $32(62.7)$ & \\
\hline Tumor diameter & & & $0.003^{*}$ \\
\hline$\leq 5 \mathrm{~cm}$ & $603(64.3)$ & $22(43.1)$ & \\
\hline$>5 \mathrm{~cm}$ & $335(35.7)$ & $29(56.9)$ & \\
\hline Multiplicity & & & 0.517 \\
\hline Solitary tumor & $820(87.4)$ & $43(84.3)$ & \\
\hline Multiple tumors & $118(12.6)$ & 8 (15.7) & \\
\hline E-S grade (worst) & & & 0.191 \\
\hline I or II & $252(26.9)$ & $9(17.6)$ & \\
\hline III or IV & $686(73.1)$ & $42(82.4)$ & \\
\hline Microvascular invasion & & & $0.012^{*}$ \\
\hline Absent & $590(62.9)$ & $23(45.1)$ & \\
\hline Present & $348(37.1)$ & $28(54.9)$ & \\
\hline Glisson capsule invasion & & & 0.418 \\
\hline Absent & $801(85.4)$ & $41(80.4)$ & \\
\hline Present & $137(14.6)$ & $10(19.6)$ & \\
\hline Necrosis & & & $0.030^{*}$ \\
\hline Absent & $504(53.7)$ & $19(37.3)$ & \\
\hline Present & $434(46.3)$ & $32(62.7)$ & \\
\hline Early recurrence $^{\mathrm{a}}$ & & & $0.010^{*}$ \\
\hline Absent & $507(54.1)$ & $18(35.3)$ & \\
\hline Present & $431(45.9)$ & $33(64.7)$ & \\
\hline
\end{tabular}

Values are presented as $n(\%)$. AFP, $\alpha$-fetoprotein; NBNC, neither hepatitis B virus nor hepatitis $C$ virus; E-S grade, Edmondson-Steiner grade. * Significant $p$ value. ${ }^{\text {a }}$ Early recurrence is defined as recurrence within 2 years after surgical tumor resection.

(hazard ratio $[\mathrm{HR}]=2.722,95 \%$ confidence interval [CI] 1.889-3.922, $p<0.001$; Table 3 ) and DFS (HR $=1.901,95 \%$ CI 1.349-2.680, $p<0.001$; Table 4). In the multivariate analysis, FGF19 amplification was predicted as an independent prognostic factor for OS (HR $=2.257,95 \% \mathrm{CI}$ 1.558-3.269, $p<0.001$; Table 3), along with BCLC stage ( $p<0.001)$, a large tumor size ( $p=$ $0.016)$, multiple tumors $(p<0.001)$, microvascular invasion $(p<0.001)$, Glisson capsule invasion $(p=0.001)$, and necrosis $(p<0.001)$. In addition, FGF19 amplification was predicted 


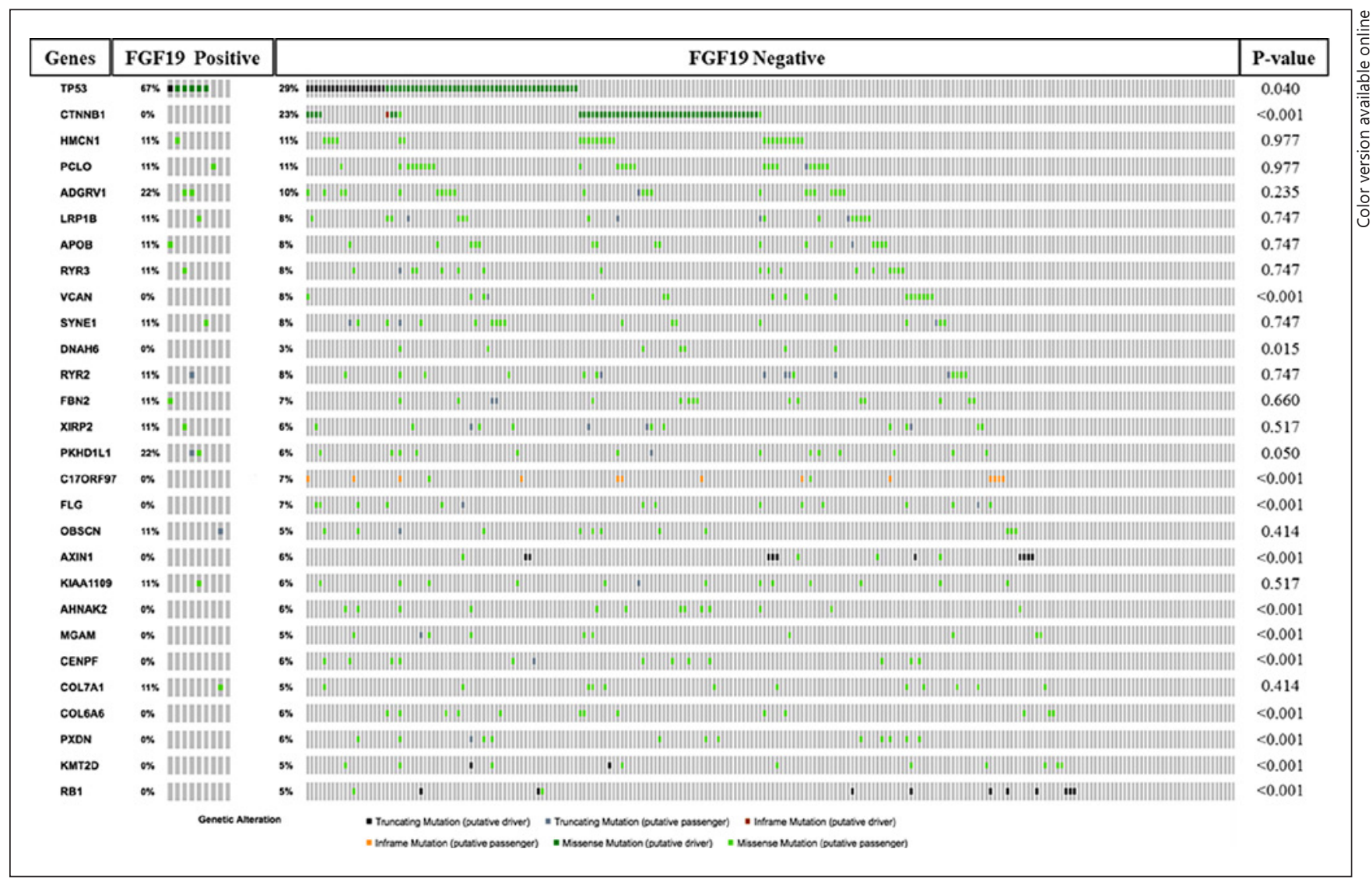

Fig. 2. Recurrent gene mutations in patients with hepatocellular carcinoma exhibiting/lacking FGF19 amplification (as determined by fluorescence in situ hybridization analysis).

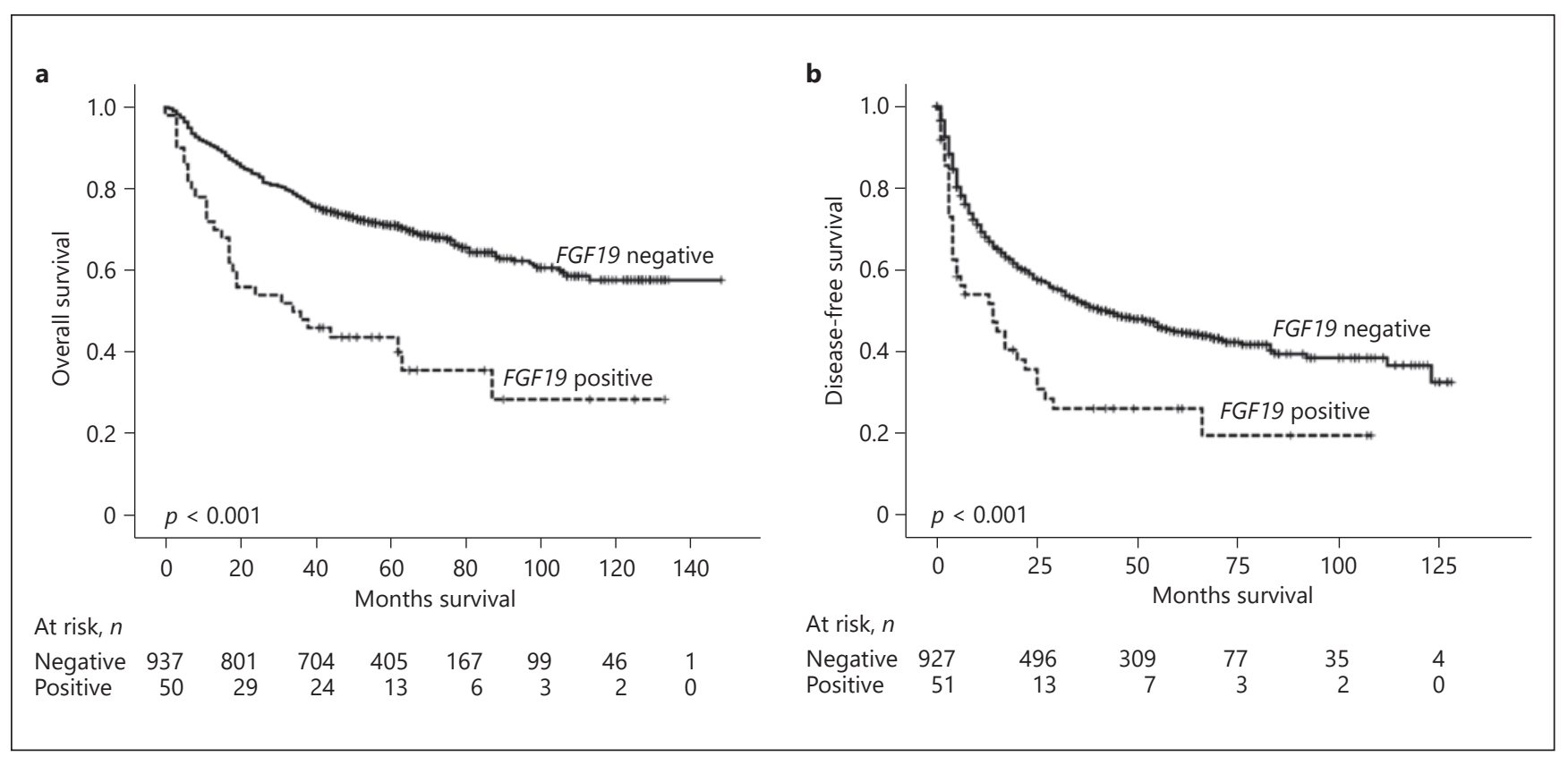

Fig. 3. Comparison of survival rates according to FGF19 amplification status. The positive group, with FGF19 amplification, was associated with poorer overall survival (a) and disease-free survival (b) rates. 


\section{Liver Cancer}

Table 3. Univariate and multivariate analyses of overall survival according to the clinicopathological variables

\begin{tabular}{l|l}
\hline Liver Cancer 2019;8:12-23 \\
\hline DOI: 10.1159/000488541 & $\begin{array}{l}\text { @ 2018 S. Karger AG, Basel } \\
\text { www.karger.com/lic }\end{array}$ \\
\hline
\end{tabular}

\begin{tabular}{lccc}
\hline & HR & $95 \%$ CI & $p$ \\
\hline Univariate analysis & & & \\
Age $\leq 50$ years & 1.320 & $1.052-1.658$ & $0.017^{*}$ \\
Male gender & 0.920 & $0.708-1.197$ & 0.536 \\
Serum AFP >100 ng/mL & 1.694 & $1.365-2.101$ & $<0.001^{*}$ \\
Hepatitis B & 1.112 & $0.845-1.463$ & 0.449 \\
Liver cirrhosis & 1.081 & $0.870-1.344$ & 0.483 \\
BCLC stage C or D & 3.047 & $2.391-3.884$ & $<0.001^{*}$ \\
Tumor diameter $>5$ cm & 2.665 & $2.145-3.310$ & $<0.001^{*}$ \\
Multiple tumors & 1.832 & $1.387-2.420$ & $<0.001^{*}$ \\
E-S grade III or IV (worst) & 1.399 & $1.215-1.610$ & $<0.001^{*}$ \\
Microvascular invasion & 3.201 & $2.570-3.987$ & $<0.001^{*}$ \\
Glisson capsule invasion & 2.396 & $1.873-3.066$ & $<0.001^{*}$ \\
Necrosis & 2.676 & $2.132-3.360$ & $<0.001^{*}$ \\
FGF19 amplification & 2.722 & $1.889-3.922$ & $<0.001^{*}$ \\
\hline Multivariate analysis & & & \\
Age $\leq 50$ years & 0.962 & $0.762-1.215$ & 0.746 \\
Serum AFP >100 ng/mL & 1.093 & $0.867-1.379$ & 0.450 \\
BCLC stage C or D & 1.845 & $1.424-2.391$ & $<0.001^{*}$ \\
Tumor diameter $>5$ cm & 1.367 & $1.060-1.764$ & $0.016^{*}$ \\
Multiple tumors & 1.747 & $1.319-2.315$ & $<0.001^{*}$ \\
E-S grade III or IV & 1.197 & $0.888-1.614$ & 0.239 \\
Microvascular invasion & 2.012 & $1.570-2.577$ & $<0.001^{*}$ \\
Glisson capsule invasion & 1.539 & $1.190-1.990$ & $0.001^{*}$ \\
Necrosis & 1.600 & $1.239-2.066$ & $<0.001^{*}$ \\
FGF19 amplification & 2.257 & $1.558-3.269$ & $<0.001^{*}$ \\
\hline & & & \\
\hline
\end{tabular}

AFP, $\alpha$-fetoprotein; HR, hazard ratio; CI, confidence interval; E-S grade, Edmondson-Steiner grade. * Significant $p$ value.

as an independent prognostic factor for DFS (HR $=1.644,95 \%$ CI 1.163-2.324, $p=0.005$; Table 4$)$, along with BCLC stage ( $p=0.017)$, a large tumor size $(p<0.001)$, multiple tumors $(p<0.001)$, microvascular invasion $(p<0.001)$, and necrosis $(p=0.008)$.

\section{Comparison of the FISH Method with the CNV Results}

We evaluated the reproducibility of the FGF19 amplification previously detected by CNV analysis using CytoScan HD data analysis on 227 HCC cases [10]. Cohen's kappa statistics showed agreement between the two methods for 219 of the 227 cases (concordance percentage: $96 \%, \kappa=0.618, p<0.001$ ). Of the 8 discrepant cases, 3 were positive for $F G F 19$ amplification by FISH and negative in the CNV analysis, whereas 5 were negative by FISH and positive in the $\mathrm{CNV}$ analysis (Table 5).

\section{Discussion}

This study evaluated FGF19 amplification using FISH in a large cohort of patients with HCC. Our main finding was that FGF19 amplification was independently associated with poor survival and with a higher risk of tumor recurrence. In accordance with this observation, FGF19 amplification was found to be significantly associated with poor prognostic factors, such as a high $\alpha$-fetoprotein level, hepatitis B or C infection, a large tumor size, microvascular 


\section{Liver Cancer}

Table 4. Univariate and multivariate analyses of disease-free survival according to the clinicopathological variables

\begin{tabular}{l|l}
\hline Liver Cancer 2019;8:12-23 \\
\hline DOI: 10.1159/000488541 & $\begin{array}{l}\text { () 2018 S. Karger AG, Basel } \\
\text { www.karger.com/lic }\end{array}$ \\
\hline
\end{tabular}

Kang et al.: Characterization of HCC Patients with FGF19 Amplification

\begin{tabular}{|c|c|c|c|}
\hline & HR & $95 \% \mathrm{CI}$ & $p$ \\
\hline \multicolumn{4}{|l|}{ Univariate analysis } \\
\hline Age $\leq 50$ years & 1.268 & $1.058-1.520$ & $0.010^{*}$ \\
\hline Male gender & 1.002 & $0.809-1.241$ & 0.985 \\
\hline Serum AFP > $100 \mathrm{ng} / \mathrm{mL}$ & 1.474 & $1.242-1.751$ & $<0.001^{*}$ \\
\hline Hepatitis B & 0.972 & $0.773-1.223$ & 0.810 \\
\hline Liver cirrhosis & 1.090 & $0.917-1.295$ & 0.330 \\
\hline BCLC stage $\mathrm{C}$ or $\mathrm{D}$ & 2.080 & $1.673-2.585$ & $<0.001^{*}$ \\
\hline Tumor diameter $>5 \mathrm{~cm}$ & 2.685 & $2.261-3.189$ & $<0.001 *$ \\
\hline Multiple tumors & 1.539 & $1.215-1.951$ & $<0.001^{*}$ \\
\hline E-S grade III or IV (worst) & 1.487 & $1.213-1.823$ & $<0.001^{*}$ \\
\hline Microvascular invasion & 2.187 & $1.842-2.597$ & $<0.001 *$ \\
\hline Glisson capsule invasion & 1.778 & $1.425-2.218$ & $<0.001^{*}$ \\
\hline Necrosis & 2.026 & $1.704-2.408$ & $<0.001^{*}$ \\
\hline FGF19 amplification & 1.901 & $1.349-2.680$ & $<0.001^{*}$ \\
\hline \multicolumn{4}{|l|}{ Multivariate analysis } \\
\hline Age $>50$ years & 0.923 & $0.766-1.112$ & 0.399 \\
\hline Serum AFP > $100 \mathrm{ng} / \mathrm{mL}$ & 1.090 & $0.908-1.309$ & 0.355 \\
\hline BCLC stage $\mathrm{C}$ or $\mathrm{D}$ & 1.324 & $1.052-1.668$ & $0.017^{*}$ \\
\hline Tumor diameter $>5 \mathrm{~cm}$ & 1.957 & $1.605-2.385$ & $<0.001^{*}$ \\
\hline Multiple tumors & 1.646 & $1.295-2.092$ & $<0.001^{*}$ \\
\hline E-S grade III or IV (worst) & 1.110 & $0.894-1.378$ & 0.343 \\
\hline Microvascular invasion & 1.535 & $1.267-1.861$ & $<0.001 *$ \\
\hline Glisson capsule invasion & 1.158 & $0.918-1.459$ & 0.215 \\
\hline Necrosis & 1.305 & $1.073-1.587$ & $0.008^{*}$ \\
\hline FGF19 amplification & 1.644 & $1.163-2.324$ & $0.005^{*}$ \\
\hline
\end{tabular}

AFP, $\alpha$-fetoprotein; HR, hazard ratio; CI, confidence interval; E-S grade, Edmondson-Steiner grade. ${ }^{*}$ Significant $p$ value.

Table 5. Concordance between the FISH and CNV results

\begin{tabular}{|c|c|c|c|c|c|}
\hline \multirow[t]{2}{*}{ CNV analysis } & \multicolumn{4}{|l|}{ FISH } & \multirow{2}{*}{$\begin{array}{l}p \text { value } \\
<0.001\end{array}$} \\
\hline & $\begin{array}{l}\text { positive } \\
\text { (amplification) }\end{array}$ & $\begin{array}{l}\text { negative } \\
\text { (no amplification) }\end{array}$ & equivocal & total & \\
\hline No amplification & 3 & 212 & 0 & 215 & \\
\hline Amplification & 7 & 5 & 0 & 12 & \\
\hline Total & 10 & 217 & 0 & 227 & \\
\hline
\end{tabular}

FISH, fluorescence in situ hybridization; CNV, copy number variation.

invasion, and necrosis. This finding supports the hypothesis that the FGF19-FGFR4 signaling pathway plays an import role in hepatocarcinogenesis $[11,18]$.

We also investigated the tentative relationship between FGF19 amplification and cirrhosis, especially in hepatitis B virus-related HCC, as observed in our previous study [10]. In the present study, which included a larger cohort, we found no relationship between FGF19 amplification and cirrhosis. However, FGF19 amplification was significantly associated with chronic HBV infection. Interestingly, a recent study reported an association between increased 


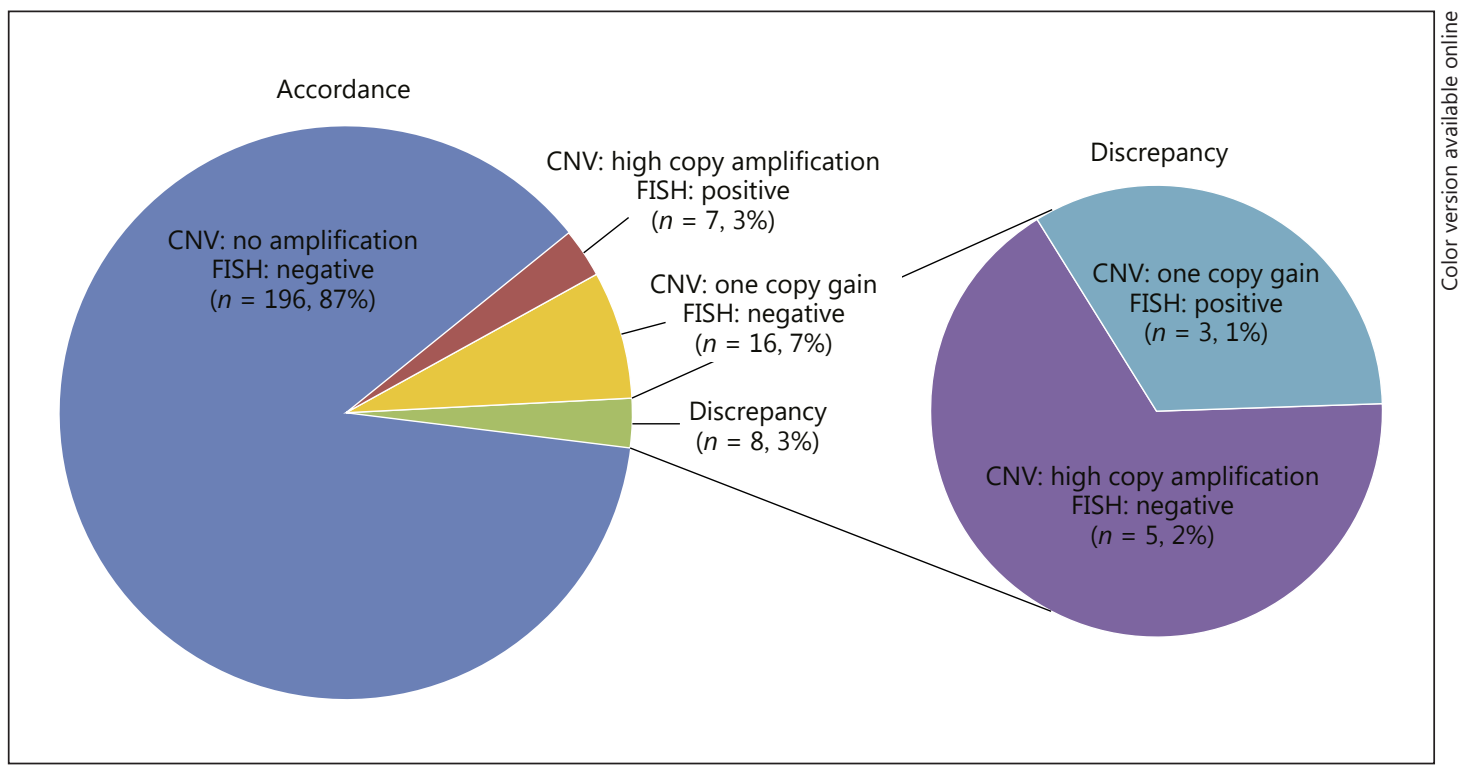

Fig. 4. Comparison of the detailed results between fluorescence in situ hybridization (FISH) and copy number variation (CNV) analyses. Among 227 cases, 219 (96\%) were matched by the CNV analysis and FISH results. Of the $8(3 \%)$ discrepant cases, $3(1 \%)$ were positive by FISH with one copy gain in the CNV analysis, whereas 5 (2\%) were negative by FISH with high copy amplification in the CNV analysis.

FGF19 level and noncirrhotic patients [22]. Additional studies will be required to provide further clarification of the significance of the FGF19-cirrhosis relationship.

Aberrant FGF1 9-FGFR4 signaling in HCC has been the focus of a number of clinical studies. BLU9931, a selective small molecule FGFR4 inhibitor, was recently shown to inhibit aberrant FGF19-FGFR4 signaling [3, 23, 24]. In another study, treatment with an anti-FGF19 antibody in liver and colon cancer xenograft models has suggested that inactivation of FGF19-mediated signaling may be beneficial for the treatment of liver cancer and other malignancies involving the interaction of FGF19 and FGFR4 [25]. We believe our current study outlines an optimal approach to identifying the most appropriate candidates for treatment, but further studies are required to investigate the clinical application of anti-FGF19 agents.

Previous investigators have reported the rate of FGF19 amplification by CNV analysis to be 5-9\% [4, 10], but the correlation between FGF19 gene status assessed by CNV and that assessed by FISH has not previously been reported. Our study showed a concordance rate between CNV results and FISH assays of approximately 96\%, suggesting that CNV data are largely reproducible using FISH, thus providing confirmation of our main study findings. However, a slight discrepancy (8 cases, 3\%) was observed (Fig. 4). From our retrospective review of the detailed results of both FISH and CNV analyses for all cases, 3 of the 19 cases with one copy gain in the CNV analysis showed FGF19 amplification according to FISH, which may be due to the low sensitivity of CNV arrays at lower tumor purity levels $[26,27]$. We selected only high copy amplifications in CNV analysis to minimize false positives and increase the specificity. In addition, 5 cases with high copy amplification in CNV analysis were seen to be FISH negative. This discrepancy may be due to the limited resolution with FISH or issues associated with the formalin fixing process, such as a delay between tissue sampling and processing, or incomplete fixation. Reducing the time between tissue collection and fixation, as well as ensuring complete fixation, will improve the quality of FISH assays. 
In summary, this study is the first to demonstrate a relationship between FGF19 amplification and the clinicopathological characteristics of HCC in a large cohort using FISH. Our findings support the hypothesis that the FGF19-FGFR4 signaling pathway plays an important role in hepatocarcinogenesis and that HCC with FGF19 amplification represents a unique molecular subtype of patients with poor prognostic characteristics who may benefit from anti-FGF19 therapeutic strategies. In addition, the observed correlation between FISH and CNV results suggests that the FISH methodology can be used with confidence to detect FGF19 amplification in patients with HCC.

\section{Statement of Ethics}

This study was approved by the Institutional Review Board of Asan Medical Center with a waiver of informed consent (IRB No. 2017-0875).

\section{Disclosure Statement}

No potential conflicts of interest are disclosed.

\section{Funding Sources}

This research was supported by a grant from the Korea Health Technology R\&D Project through the Korea Health Industry Development Institute, funded by the Ministry of Health and Welfare (HI16C1985) and by the Basic Science Research Program through the National Research Foundation of Korea funded by the Ministry of Science, ICT, and future Planning (NRF-2015R1A2A2A04004063).

\section{References}

1 Torrecilla S, Llovet JM: New molecular therapies for hepatocellular carcinoma. Clin Res Hepatol Gastroenterol 2015;39(suppl 1):S80-S85.

2 Guichard C, Amaddeo G, Imbeaud S, Ladeiro Y, Pelletier L, Maad IB, Calderaro J, Bioulac-Sage P, Letexier M, Degos F, Clément B, Balabaud C, Chevet E, Laurent A, Couchy G, Letouzé E, Calvo F, Zucman-Rossi J: Integrated analysis of somatic mutations and focal copy-number changes identifies key genes and pathways in hepatocellular carcinoma. Nat Genet 2012;44:694-698.

3 Hagel M, Miduturu C, Sheets M, Rubin N, Weng W, Stransky N, Bifulco N, Kim JL, Hodous B, Brooijmans N, Shutes A, Winter C, Lengauer C, Kohl NE, Guzi T: First selective small molecule inhibitor of FGFR4 for the treatment of hepatocellular carcinomas with an activated FGFR4 signaling pathway. Cancer Discov 2015;5: 424-437.

4 Kaibori M, Sakai K, Ishizaki M, Matsushima H, De Velasco MA, Matsui K, Iida H, Kitade H, Kwon AH, Nagano H, Wada H, Haji S, Tsukamoto T, Kanazawa A, Takeda Y, Takemura S, Kubo S, Nishio K: Increased FGF19 copy number is frequently detected in hepatocellular carcinoma with a complete response after sorafenib treatment. Oncotarget 2016;7:49091-49098.

5 Revill K, Wang T, Lachenmayer A, Kojima K, Harrington A, Li J, Hoshida Y, Llovet JM, Powers S: Genome-wide methylation analysis and epigenetic unmasking identify tumor suppressor genes in hepatocellular carcinoma. Gastroenterology 2013;145:1424-1435.e1-e25.

6 Villanueva A, Llovet JM: Liver cancer in 2013: mutational landscape of HCC - the end of the beginning. Nat Rev Clin Oncol 2014;11:73-74.

7 Nault JC, Zucman-Rossi J: TERT promoter mutations in primary liver tumors. Clin Res Hepatol Gastroenterol 2016;40:9-14.

8 Woo HG, Wang XW, Budhu A, Kim YH, Kwon SM, Tang ZY, Sun Z, Harris CC, Thorgeirsson SS: Association of TP53 mutations with stem cell-like gene expression and survival of patients with hepatocellular carcinoma. Gastroenterology 2011;140:1063-1070.e8.

9 Villanueva A, Portela A, Sayols S, Battiston C, Hoshida Y, Méndez-González J, Imbeaud S, Letouzé E, HernandezGea V, Cornella H, Pinyol R, Solé M, Fuster J, Zucman-Rossi J, Mazzaferro V, Esteller M, Llovet JM: DNA methylation-based prognosis and epidrivers in hepatocellular carcinoma. Hepatology 2015;61:1945-1956. 
Kang et al.: Characterization of HCC Patients with FGF19 Amplification

10 Ahn SM, Jang SJ, Shim JH, Kim D, Hong SM, Sung CO, Baek D, Haq F, Ansari AA, Lee SY, Chun SM, Choi S, Choi HJ, Kim J, Kim S, Hwang S, Lee YJ, Lee JE, Jung WR, Jang HY, Yang E, Sung WK, Lee NP, Mao M, Lee C, ZucmanRossi J, Yu E, Lee HC, Kong G: Genomic portrait of resectable hepatocellular carcinomas: implications of RB1 and FGF19 aberrations for patient stratification. Hepatology 2014;60:1972-1982.

11 Kan Z, Zheng H, Liu X, Li S, Barber TD, Gong Z, Gao H, Hao K, Willard MD, Xu J, et al: Whole-genome sequencing identifies recurrent mutations in hepatocellular carcinoma. Genome Res 2013;23:1422-1433.

12 Totoki Y, Tatsuno K, Covington KR, Ueda H, Creighton CJ, Kato M, Tsuji S, Donehower LA, Slagle BL, Nakamura $\mathrm{H}$, et al: Trans-ancestry mutational landscape of hepatocellular carcinoma genomes. Nat Genet 2014;46:12671273.

13 Schulze K, Imbeaud S, Letouzé E, Alexandrov LB, Calderaro J, Rebouissou S, Couchy G, Meiller C, Shinde J, Soysouvanh F, Calatayud AL, Pinyol R, Pelletier L, Balabaud C, Laurent A, Blanc JF, Mazzaferro V, Calvo F, Villanueva A, Nault JC, Bioulac-Sage P, Stratton MR, Llovet JM, Zucman-Rossi J: Exome sequencing of hepatocellular carcinomas identifies new mutational signatures and potential therapeutic targets. Nat Genet 2015; 47:505-511.

14 Kir S, Kliewer SA, Mangelsdorf DJ: Roles of FGF19 in liver metabolism. Cold Spring Harb Symp Quant Biol 2011; 76:139-144

$15 \mathrm{Wu}$ X, Li Y: Role of FGF19 induced FGFR4 activation in the regulation of glucose homeostasis. Aging (Albany NY) 2009;1:1023-1027.

16 Miura S, Mitsuhashi N, Shimizu H, Kimura F, Yoshidome H, Otsuka M, Kato A, Shida T, Okamura D, Miyazaki M: Fibroblast growth factor 19 expression correlates with tumor progression and poorer prognosis of hepatocellular carcinoma. BMC Cancer 2012;12:56.

17 Nicholes K, Guillet S, Tomlinson E, Hillan K, Wright B, Frantz GD, Pham TA, Dillard-Telm L, Tsai SP, Stephan JP, Stinson J, Stewart T, French DM: A mouse model of hepatocellular carcinoma: ectopic expression of fibroblast growth factor 19 in skeletal muscle of transgenic mice. Am J Pathol 2002;160:2295-2307.

18 Sawey ET, Chanrion M, Cai C, Wu G, Zhang J, Zender L, Zhao A, Busuttil RW, Yee H, Stein L, French DM, Finn RS, Lowe SW, Powers S: Identification of a therapeutic strategy targeting amplified FGF19 in liver cancer by oncogenomic screening. Cancer Cell 2011;19:347-358.

19 French DM, Lin BC, Wang M, Adams C, Shek T, Hötzel K, Bolon B, Ferrando R, Blackmore C, Schroeder K, Rodriguez LA, Hristopoulos M, Venook R, Ashkenazi A, Desnoyers LR: Targeting FGFR4 inhibits hepatocellular carcinoma in preclinical mouse models. PLoS One 2012; 7:e36713.

20 Hyeon J, Ahn S, Lee JJ, Song DH, Park CK: Expression of fibroblast growth factor 19 is associated with recurrence and poor prognosis of hepatocellular carcinoma. Dig Dis Sci 2013;58:1916-1922.

21 Wolff AC, Hammond ME, Hicks DG, Dowsett M, McShane LM, Allison KH, Allred DC, Bartlett JM, Bilous M, Fitzgibbons P, Hanna W, Jenkins RB, Mangu PB, Paik S, Perez EA, Press MF, Spears PA, Vance GH, Viale G, Hayes DF: Recommendations for human epidermal growth factor receptor 2 testing in breast cancer: American Society of Clinical Oncology/College of American Pathologists clinical practice guideline update. Arch Pathol Lab Med 2014;138:241-256.

22 Wunsch E, Milkiewicz M, Wasik U, Trottier J, Kempińska-Podhorodecka A, Elias E, Barbier O, Milkiewicz P: Expression of hepatic fibroblast growth factor 19 is enhanced in primary biliary cirrhosis and correlates with severity of the disease. Sci Rep 2015;5:13462.

23 Repana D, Ross P: Targeting FGF19/FGFR4 pathway: a novel therapeutic strategy for hepatocellular carcinoma. Diseases 2015;3:294-305.

24 Katoh M: FGFR inhibitors: effects on cancer cells, tumor microenvironment and whole-body homeostasis (review). Int J Mol Med 2016;38:3-15.

25 Desnoyers LR, Pai R, Ferrando RE, Hötzel K, Le T, Ross J, Carano R, D’Souza A, Qing J, Mohtashemi I, Ashkenazi A, French DM: Targeting FGF19 inhibits tumor growth in colon cancer xenograft and FGF19 transgenic hepatocellular carcinoma models. Oncogene 2008;27:85-97.

26 Coughlin CR 2nd, Scharer GH, Shaikh TH: Clinical impact of copy number variation analysis using high-resolution microarray technologies: advantages, limitations and concerns. Genome Med 2012;4:80.

27 Stevens-Kroef MJ, van den Berg E, Olde Weghuis D, Geurts van Kessel A, Pfundt R, Linssen-Wiersma M, Benjamins M, Dijkhuizen T, Groenen PJ, Simons A: Identification of prognostic relevant chromosomal abnormalities in chronic lymphocytic leukemia using microarray-based genomic profiling. Mol Cytogenet 2014; $7: 3$. 